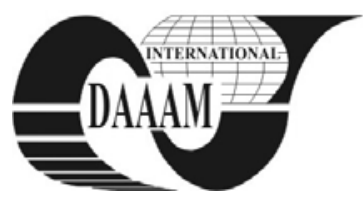

\title{
INNOVATION AND KNOWLEDGE CREATION MECHANISMS
}

\author{
TEKIC, Z[eljko]; COSIC, I[lija] \& KATALINIC, B[ranko]
}

\begin{abstract}
This paper describes a conceptual model that links knowledge and innovation. It contributes to understanding the role of knowledge within a firm by exploring dominant knowledge creating mechanisms which lead to innovations as well as resulting innovations.
\end{abstract}

Key words: model, knowledge creation, innovation, historiography

\section{INTRODUCTION}

Natural resources and other tangible assets no longer determine the fortunes of economies. In a globalised world where markets, products, technologies, competitors, regulations, and even societies change rapidly, new market disequilibrium situations and, consequently, new profit opportunities arise from continuous changes in the state of knowledge (Jacobson, 1992). In such environment, knowledge and knowledge-based assets are recognised as a major source of sustainable competitive advantage.

However, what is crucial for the success of organisations at all levels is not just the ability to understand, process, and generate advanced knowledge, but to transfer it into marketable innovations as well. The generation of innovations is seen as an engine of growth for many firms. Innovations help companies to open new and to satisfy the emerging needs of existing markets. On the other hand, dynamic changes of knowledge during its life cycle make a strategic challenge for companies regarding the right way to access, store, identify, develop, protect, conserve and share knowledge even more difficult.

Although knowledge and innovation have a strong relationship, this relationship has not been completely understood; especially how knowledge is transferred into an innovation. Although modelling is a very useful approach for this, there are no comprehensive models that link knowledge and innovation. Current models mostly represent inventive process as the flow of knowledge (idea) through several stages, including: research, invention, development and application, where new opportunities arise out of the 'technology push' or 'market pull'. The other very influential framework is based on tacit and explicit knowledge, where the relationships between these types serve as the core basis for innovation model (Nonaka and Takeuchi, 1995).

The purpose of this paper is to provide a greater understanding of the knowledge - innovation interface by explaining knowledge creating mechanisms and linking them to innovation results.

\section{LITERATURE REVIEW}

Knowledge is essential to innovation, but an exposure to a problem is generally considered to be the initiator of the innovation process (Nonaka and Takeuchi, 1995). The knowledge needed to solve the problem is not created at one place or by one company only. It is cumulatively co-created in a dialectical process, in which various contradictions are synthesized through dynamic interactions among individuals, the organization, and the environment (Nonaka and Takeuchi, 1995). Different firms know how to do different things in different ways. Their success depends on how much they "know" and how well they explore what they "know".

Innovation and knowledge are seen as two faces of the same coin. Anand et al. (2007) define innovation as generation and exploitation of new forms of knowledge, while Katila and Katila and Chen (2008) see innovation as the problem-solving process in which organisations manipulate knowledge to create new products. Recently, Quintane et al. (2011) describe innovation as duplicable knowledge which is new in the context it is introduced to and useful in practice. We define innovation as a sustainable and value-adding solution to a problem that is created by applying the new or recombining the existing knowledge.

\section{METHODOLOGY}

In this research we use historiography as an empirical research paradigm. Knowledge and innovations as well as their management, emerge within a linear time frame as technologies, societies and organisations evolve in response to various internal and external forces. As a linear and, thus, historical concept, the knowledge - innovation interface can be studied using evidence of past events and decisions. Following this logic, our research focuses on a chronology of knowledge and innovation development in telephone industry from the middle of $18^{\text {th }}$ century until today in order to obtain a fuller and richer understanding of knowledge - innovation links. Based on primary (patent data, photos, interviews, industry memos and contracts) and secondary (scientific, technical and newspaper articles, books, PhD theses and market reports) evidence, we track the development of knowledge and related innovations in fix, mobile and smart phone industry.

In order to successfully manage innovation, it is important to better understand knowledge - innovation interface. In this case, historiography is a useful approach because there is a high possibility that the current situation is a part of a cycle and that understanding the nature of the cycle would help the current situation (O’Brien et al., 2004).

\section{RESULTS}

The links and interdependences between knowledge and innovation can be represented by the "House of knowledge" model (Tekic et al., 2010). The model describes not only how new knowledge is created through interactions and feedbacks, but also how different pieces of knowledge (new and old) become combined in new ways to produce innovations. Understanding different processes and stages in the knowledge development is a way towards the ability to create and utilize unique, valuable, difficult to imitate, and difficult to substitute knowledge (Teece et al., 1997).

Along the model, we identified that knowledge progresses through five stages of innovation (Figure 1): innovation as a concept (point A), innovation as a creation, (B), innovation as 
an integration (C), innovation as an optimisation (D) and innovation as an extension/deviation (E). The stages of innovation are linked by five dominant knowledge creation mechanisms: ideatisation - knowledge creation (arrow line coming to A), competition - competitors' knowledge cocreation (arrow line between A and B), convergence - interindustry knowledge co-creation, (arrow line between B and C), customisation- user-producer knowledge co-creation (arrow lines between $\mathrm{C}$ and $\mathrm{D}$ ) and extension - user-user knowledge co-creation (line between $\mathrm{D}$ and $\mathrm{E}$ ). None of these mechanisms is exclusively present at one stage or only at one stage.

This means that every link between two innovation stages is a result of a combination of several of them.

\begin{tabular}{|l|}
\hline Knowledge creation mechanism \\
\hline Ideatisation \\
- Creation of new to the world and unstructured \\
knowledge in order to solve incompletely defined \\
problem (the environment description and the purpose \\
are incomplete). \\
- The result is innovation as a concept \\
- Creation of the first workable solution \\
- Knowledge is created among individuals (Industry does \\
not exist)
\end{tabular}

\section{Competition}

- Based on created concept, competitors add one upon another new layer of applicable knowledge in order to solve the key problem. (Key problems: signal attenuation over distance and network system for fixed telephony; frequency reuse, phone size and energy inefficiency for mobile telephony; network optimize for voice transfer for smart phones)

- The result is innovation as a creation

- Creation of the sustainable solution

- Knowledge is created inside industry, among competitors

- Created knowledge is new to the world and get structure based on the concept

\section{Convergence}

- Created solution is advanced by application of knowledge originally developed in other industry and for other industry. (The most influential is integration with the main technology trend: microelectronics, digitalisation and microprocessors)

- The result is innovation as a integration

- Advancement of original solution

- Knowledge is structured and originally developed in other industry and for other industry (new for the industry).

\section{Customisation}

- Solution is further developed by the application of new knowledge that is created in company lead communication with users

- The resut is innovation as a optimisation

- Optimisation of original solution and adaptation to specific needs

- Knowledge is created between company and users, it is structured and new to the company

\section{Extension}

- Solution is getting the new functionality by applying knowledge created following user - user relationship,

- Company does not lead process

- The result is innovatin as a adaptation/deviation

- Knowledge is unstructured and new to the company. Sometimes it can be new to the world

Tab. 1. Knowledge creation mechanism

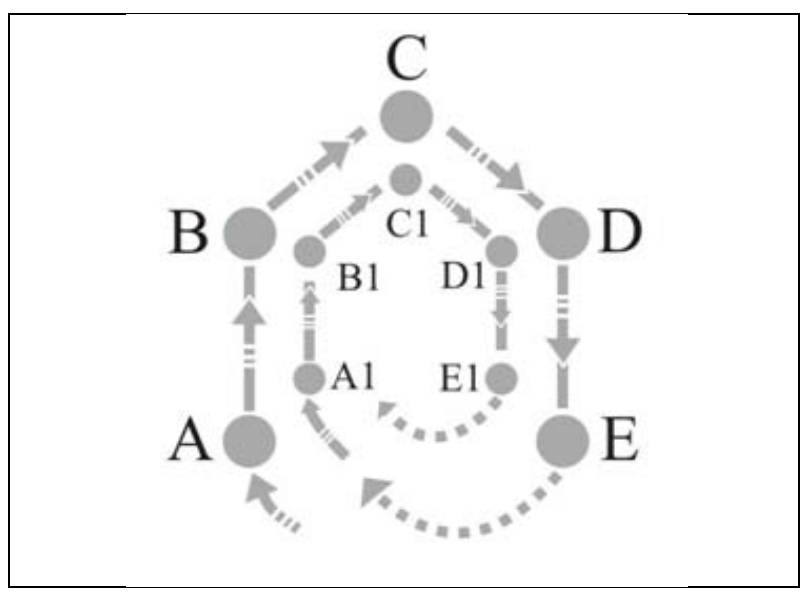

Fig. 1. House of Knowledge - Knowledge-Innovation Cycle

However, one always dominates. Table 1 summarises characteristics of the identified innovation stages and knowledge creating mechanisms.

\section{CONCLUSION}

The outlined model contributes to understanding the way in which firms recognise and access to knowledge in order to mobilize and utilise the knowledge to produce a product, service or new knowledge. The application of the model should help in choosing the right knowledge management tools at the specific stage of the knowledge-innovation cycle, which is crucial for achieving sustainable results.

The limitations of our research are inherent to modeling task. Therefore, further research should explore recognized links and support model validity through case study evidence.

\section{REFERENCES}

Anand, N.; Gardner, H.K. \& Morris, T. (2007). Knowledgebased Innovation: Emergence and Embedding of New Practice Areas in Management Consulting Firms. Academy of Management Journal, Vol. 50, Vol. 2, pp. 406-428. ISSN $0001-4273$

Jacobson, R. (1992). The Austrian school of strategy. Academy of Management Review, Vol. 17, No. 4, pp. 782-807., ISSN 0363-7425

Katila, R. \& Chen, E.L. (2008). Effects of Search Timing on Innovation: The Value of Not Being in Sync with Rival. Administrative Science Quarterly, Vol. 53, pp. 593-625., ISSN $0001-8392$

Nonaka, I. \& Takeuchi, H. (1995) The Knowledge Creating Company, Oxford University Press, ISBN 0195092694, Oxford.

O’Brien, J.; Remenyi, D. \& Keaney, A. (2004). Historiography - A Neglected Research Method in Business and Management Studies. Electronic Journal of Business Research Methods, Vol. 2, Iss 2, pp. 135-144, ISSN 14777029

Quintane, E.; Casselman, M., Reiche, B.S. \& Nylund, P. (2011). Innovation as a Knowledge-Based Outcome. Journal of Knowledge Management, Vol. 15 Iss: 6, ISSN: 1367-3270

Teece, D., Pisano, G. \& Shuen, A. (1997). Dynamic capabilities and strategic management. Strategic Management Journal, Vol. 18, No. 7, pp 509 - 533., ISSN 0143-2095

Tekic, Z.; Cosic, I. \& Katalinic, B. (2010). Framing knowledge in business context, Annals of DAAAM for 2010 \& Proceedings of the 21th International DAAAM Symposium, Katalinic, B. (Ed), pp 555-557, ISSN 1726-9679, DAAAM International, Vienna, Austria 2010 